\title{
Comparative study between Open and Laparoscopic Appendectomy in Complicated Cases
}

\section{E.A.Sadek, G.E.Saleh M.T.Youness and S.A.El-gazzar}

General surgery Dept., Faculty of Medicine, Benha Univ., Benha, Egypt

E-mail:Mohammed.Atef21@fmed.bu.edu.eg

\begin{abstract}
Background: Acute appendicitis is the most common cause of the acute abdomen requiring surgery with a lifetime risk of $6 \%-8 \%$, which is maximal in childhood and declines steadily with age as the lymphoid tissue and vascularity atrophy.

The aim of the present study was to Compare between Open and laparoscopic appendectomy in complicated cases as regard post-operative improvement (Pain, leakage, sepsis, hospital stay, return to work).

This study was a Prospective non randomized study which included100 patients (50 open technique , 50 laparoscopic technique ) from emergency department at Benha University Hospital and. Through one year started from $1^{\text {st }}$ of may 2020 to $30^{\text {th }}$ of april 2021 .
\end{abstract}

Keywords: laproscopic open appendectomy.

\section{Introduction}

Appendix, formally vermiform appendix, anatomically, is a vestigial hollow tube that is closed at one end and is attached at the other end to the cecum, a pouch like beginning of the large intestine into which the small intestine empties its contents, The appendix is usually 8 to $10 \mathrm{~cm}$ (3 to 4 inches) long and less than $1.3 \mathrm{~cm}(0.5 \mathrm{inch})$ wide. The cavity of the appendix is much narrower where it joins the cecum than it is at its closed end [1].

The appendix has muscular walls that are ordinarily capable of expelling into the cecum the mucous secretions of the appendiceal walls or any of the intestinal contents that have worked their way into the structure [2].

Appendicitis is defined as an inflammation of the inner lining of the vermiform appendix that spreads to its other parts. Despite diagnostic and therapeutic advancement in medicine, appendicitis remains a clinical emergency and is one of the most common causes of acute abdominal pain [3].

The inflammation in acute appendicitis may sometimes be fixed by the patient's own defense mechanisms, by the formation of an inflammatory mass (an appendiceal-phlegmon) or circumscribed abscess (an appendiceal abscess),often presenting as a palpable mass days following the onset of symptoms. This complication occurs in 2 to $7 \%$ of all cases of appendicitis [4].

Controversy continues over the operative approach to appendectomy. Open appendectomy has traditionally been the most common approach, because it is quick and cost-effective. However, an increasing number surgeons prefer laparoscopic appendectomy because of the diagnostic ability of laparoscopy, especially in female patients [5].

The aesthetic results and an earlier return to normal activities may also be advantageous. [6]

McBurney's procedure represented the goldstandard for acute appendicitis until1981, number of laparoscopic appendectomies has progressively increased since it has been demonstrated to be a safe procedure, with excellent cosmetic results and it also allows a shorter hospitalization, a quicker and less painful postoperative recovery. [7]

The minimally invasive laparoscopic technique is safe and efficacious. It should be the initial procedure of choice for most cases of complicated appendicitis. [8]

The morbidity rates mainly for intra-abdominal abscesses and wound infection were less in laparoscopic appendectomy than in open appendectomy whereas operating times and hospital stays were similar. [9]

\section{Aim of the work}

The aim of this study is to Compare between Open and laparoscopic appendectomy in complicated cases as regard post-operative improvement (Pain, leakage, sepsis, hospital stay, return to work).

\section{Patients and Methods}

\subsection{Patients Selection:}

Prospective study non randomized, Non probability, Purposive Sampling from emergency department at Benha University Hospital and. Through one year started from $1^{\text {st }}$ of may 2020 to $30^{\text {th }}$ of april 2021.

100 patients were enrolled in this study with symptoms and signs of complicated appendicitis including acute onset abdominal pain mainly in right lower quadrant, nausea, vomiting, anorexia, elevated temperature and right lower quadrant tenderness and rebound \& crossed tenderness, presecene of mass \& abcess. Also preoperative consents were discussed and obtained from all patients according to approved standards of The Ethical committee of Benha University.

Preoperatively a record of their medical history, physical examinations, labs values including CBC, Radiological ( U/S , C.T ) and patients were classified according to their results to be +ve or -ve. Alvarado score was also calculated for all patients with suspected acute appendicitis and was recorded in their files. 
Intraoperatively both open and laparoscopic appendectomy operations were used in this study. Each removed appendix was classified according its gross appearance to be suppurative, perforated or gangrenous, Presence of app-mass or Abscess.

Postoperatively, Patients were followed up for postoperative complications as vomiting, epigastric pain, ileus, fever, diarrhea and surgical site infection and all results were recorded

\subsection{Inclusion criteria}

- Clinically and radiologically approved complicated appendicitis

(right iliac fossa pain> 2 days, rigid abdomen, fever $>38$, TLC $>15$, radiologically: free intraperitoneal fluid collection mass, C.T pelviabdomen)

- Patients from 15-60 years old.

\subsection{Exclusion criteria}

- Age less than 15 (no facilities available for this age) or more than 60 years.

- Mild acute appendicitis.

- Contraindication with laparoscope

- patients who refused to have appendectomy

All patients meeting the inclusion criteria were be subjected to our study after proper history taking, full clinical examination, and required preoperative investigations.

By computer assisted randomization, our patients will be randomized into two groups:

Group A: (50 patients) will undergo open appendectomy

Group B: (50 patients) will undergo laparoscopic appendectomy.

\subsection{Preoperative assessment (History)}

Clinical history taking included; personal history including age, occupation, and special habits of medical importance particularly smoking; complaint and its duration; history of present illness including analysis of the complaint and are view of other body systems specially chest complaints, The diagnostic sequence of colicky central abdominal pain followed by vomiting with migration of the pain to the right iliac fossa was first described by Murphy but may only be present in $50 \%$ of patients. Typically, the patient describes a peri-umbilical colicky pain, which intensifies during the first 24 hours, becoming constant and sharp, and migrates to the right iliac fossa.

\subsection{Examination}

Clinical examination included general examination including vital data; chest examination for signs of chronic obstructive lung disease; abdominal examination for abdominal masses and $P / R$ examination for prostatic enlargement; and local examination of The site of maximal tenderness is often said to be over McBurney's point, which lies two thirds of the way along a line drawn from the umbilicus to the anterior superior iliac spine.

\section{1) Investigation}

I. Investigations were requested for whenever required for patients including complete blood picture, coagulation profile, liver function tests, kidney function tests, fasting blood sugar, ECG for those patients over $40 \mathrm{~s}$ or with Trans-abdominal ultrasonography

\section{Computed tomography \\ III. MRI}

2) Differentiation of simple from complex disease

Neither CT nor emergency MRI are able to discriminate between non- perforated and perforated appendicitis, which limits clinicians' ability to objectively stratify patients for short in-hospital delays before surgery or for selection to trials of nonoperative treatment with antibiotics. Presence of an appendicolith in radiological imaging is associated with both an increased risk of antibiotic failure and recurrence, whereas the triad of C-reactive protein level below $60 \mathrm{mg} / \mathrm{L}$, white blood cell count lower than than $12 \times 10^{9}$, and age younger than 60 years has been reported to predict antibiotic success.

\section{II)Patients randomization:}

The selected patients were randomized into 2 groups by the closed envelop method.

Group A: (50 patients) will undergo open appendectomy

Group B: (50 patients) will undergo laparoscopic appendectomy.

Patients permission and education (informed consent)

All patients had given permission to take part in the study. Patients were educated about the procedure to be performed, the possible complications and their management and schedule of follow up. In- addition, patients were specially educated about how to describe their pain level at rest in the first post-operative day. Pain is expressed as: no pain, mild pain, discomforting pain (analgesia is preferred), distressing pain (analgesia is a must)

\section{Results \\ Horrible pain not responding to usual analgesics. \\ Data recorded: \\ Descriptive data about patients' characteristics including age, sex, occupation, physical activity, smoking, relevant medications, body mass index.}


Table (1) General characteristics in both groups

\begin{tabular}{llccc}
\hline & & $\begin{array}{c}\text { Group A } \\
(\mathbf{n = 5 0})\end{array}$ & $\begin{array}{c}\text { Group B } \\
(\mathbf{n = 5 0})\end{array}$ & P-value \\
\hline Age (years) & Mean \pm SD & $26 \pm 6$ & $27 \pm 8$ & 0.311 \\
& Males n (\%) & $23(46.0)$ & $27(54.0)$ & 0.424 \\
Gender & Females n $\mathbf{\%})$ & $27(54.0)$ & $23(46.0)$ & \\
Weight $(\mathbf{k g})$ & Mean \pm SD & $67 \pm 15$ & $64 \pm 14$ & 0.401 \\
\hline
\end{tabular}

Independent t-test was used for age and weight. Chi-square test was used for gender

Table (2) Pre-operative characteristics in both groups

\begin{tabular}{llccc}
\hline & & $\begin{array}{c}\text { Group A } \\
(\mathbf{n}=\mathbf{5 0})\end{array}$ & $\begin{array}{c}\text { Group B } \\
(\mathbf{n}=\mathbf{5 0})\end{array}$ & P-value \\
\hline Duration of symptoms (days) & Mean \pm SD & $5 \pm 2$ & $5 \pm 2$ & 0.634 \\
Generalized peritonitis & $\mathbf{n}(\%)$ & $12(24.0)$ & $16(32.0)$ & 0.106 \\
Pre-op TLC $\left(\mathbf{1 0}^{\mathbf{3}} \mathbf{m m 3}\right)$ & Mean \pm SD & $15 \pm 3$ & $16 \pm 4$ & 0.085 \\
\hline
\end{tabular}

Independent t-test was used duration and TLC. Chi-square test was used for peritonitis

\section{Discussion}

HISTORICALLY Claudius Amyand [10] a surgeon at St George's Hospital, London in 1735 was the first to do appendectomy operation. In 1889, Charles McBurney [11] introduced famous open appendectomy through incision and muscle splitting approach for which continued to be used until the late 20th century. In 1983, Semm [12] (a German gynecologist) performed the first laparoscopic appendectomy, Subsequently, Pier et al., reported on a large case series of laparoscopic appendectomy for acute appendicitis and demonstrated that this technique was safe and could achieve the same results as open appendectomy [13]

Acute appendicitis is one of the most common surgical emergencies, requires a basic investigations and clinical examination in diagnosis. Appendicitis is one of the commonest causes of abdominal pain. Approximately $7 \%$ of the global population develops appendicitis in their life span. According to the literature, open appendectomy has been an effective operation for acute appendicitis for more than a century, thus making appendectomy the most frequently performed abdominal operation [14]

With the great advances in technology and the surgical techniques, laparoscopic appendectomy has become the novel alternative in the treatment of appendicitis in the last 2 decades. The indications for laparoscopic appendectomy remain controversial, despite the publications of numerous randomized trials, which compared open and laparoscopic appendectomy. Some studies failed to demonstrate clear advantages of LA over OA [15]

Some authors consider laparoscopic appendicectomy a promising method regarding its less invasiveness with shorter hospital stays, less postoperative pain, less incidence of surgical site infections and reduced the risk of post-operative adhesions. Other authors consider that it has prolonged operative time \& higher cost [16]

Few studies have established that laparoscopic appendectomy has a higher incidence of intra- abdominal abscesses and difficult applicability particularly in complicated appendicitis. Besides, the risk of organ specific injuries is considered by some authors to be higher in laparoscopic appendectomy than in open appendectomy although laparoscopic appendectomy has a better view of the peritoneal cavity that in turns enables safe exploration. Generally, all laparoscopic procedures are more time consuming for the following reasons: Inherent nature of slow maneuver of laparoscopic techniques, time taken by careful slow insufflations, and routine diagnostic laparoscopy before starting any laparoscopic procedure [16].

The main aim of this study was to Compare between Open and laparoscopic appendectomy in complicated cases as regard post-operative improvement (Pain, leakage, sepsis, hospital stay, return to work).

This Prospective study non randomized, nonprobability, Purposive Sampling from emergency department at Benha University Hospital and. Through one year started from 1st of May 2020 to 30th of April 2021.Patients were randomized into two groups: Group A :(50 patients) would undergo open appendectomy and Group B: (50 patients) would undergo laparoscopic appendectomy [16].

\section{The main results of this study were as following}

There were no significant differences between both groups regarding age $(\mathrm{P}$-value $=0.311)$, gender $(\mathrm{P}$-value $=0.424)$, and weight $(\mathrm{P}$-value $=0.401)[17]$.

These results were in agreement with study of Ibraheem et al., 2021. as they reported that there was no statistically significant difference between open and laparoscopic groups according to demographic data. [18].

Also, Pradhan et al., 2015 revealed that there were 216 cases of appendectomy with $93(43.1 \%)$ male and 123 (56.9\%) female cases. They were assigned into two groups, where 106 patients underwent Open Appendectomy (OA) and 110 patients underwent Laparoscopic Appendectomy (LA). Three patients 
were converted from Laparoscopic to open appendectomy. Average age and male: female ratio was similar in both groups [19].

Muhammad et al. 2013 [20] conducted a similar study and reported that the mean age in the laparoscopic appendectomy group was $32 \pm 14$ years; the mean age of patients in the open appendectomy group was $34 \pm 13$ years. These results are quite close to the mean ages in our study. This similarity in age is because appendicitis is more common in the younger age group, as shown by Hui et al. 2002[21]. According to Lunca et al., 2004. appendicitis was most common in the 11 to 20 -year age group, but the increasing incidence in older patients may be due to increased life expectancies [22].

The appendix is a blind-ended tube connected to the cecum, from which it develops in the embryo. The most common diseases of the appendix (in humans) are appendicitis and carcinoid tumors. Appendicitis is inflammation of the appendix. Symptoms commonly include right lower abdominal pain, nausea, vomiting, and decreased appetite. However, approximately $40 \%$ of people do not have these typical symptoms. Appendicitis is caused by a blockage of the hollow portion of the appendix. This is most commonly due to a calcified "stone" made of feces. Inflamed lymphoid tissue from a viral infection, parasites, gallstone, or tumors may also cause the blockage. This blockage leads to increased pressures in the appendix, decreased blood flow to the tissues of the appendix, and bacterial growth inside the appendix causing inflammation. The combination of inflammation, reduced blood flow to the appendix and distention of the appendix causes tissue injury and tissue death. If this process is left untreated, the appendix may burst, releasing bacteria into the abdominal cavity, leading to increased complications [22].

The present study showed that there were no significant differences between both groups regarding symptoms duration $(\mathrm{P}$-value $=0.634)$, generalized peritonitis $(\mathrm{P}$-value $=0.106)$, and pre-operative TLC $(\mathrm{P}$-value $=0.0 .085)$. [23].

Our results were in line with study of Bhosle $\boldsymbol{\&}$ Degloorker, 2018 as they reported that there were no statistically significant differences between open and laparoscopic groups as regard TLC. [24].

On the contrary, Biondi et al., 2016. showed that the difference in gender and in the white blood cell count at presentation was statistically significant. Out of the total 310 open procedures, 214 (69\%) were performed for uncomplicated appendicitis and 96 (31 $\%)$ for complicated disease including appendiceal perforation with local or widespread peritonitis. In the laparoscopic group, 241 (85\%) procedures involved uncomplicated disease and $42(15 \%)$ complicated appendicitis. Noteworthy, they did not observe differences between groups for all the grades of appendicitis [25]

Appendectomy can be performed through open or laparoscopic surgery. When the surgeon uses the open approach, he makes an incision in the lower right section of the abdomen. Most incisions are less than 3 inch $(7.6 \mathrm{~cm})$ in length. The surgeon then identifies caecum and terminal ileum. The appendix is located and brought up into the wounds. The surgeon separates the appendix from all the surrounding tissue and its attachment to the cecum, and then removes it. The site where the appendix was previously attached, the cecum, is closed and returned to the abdomen, the muscle layers and then the skin is sewn together [25]

When the surgeon performs a laparoscopic appendectomy, three incisions, each about 1 in $(2.5$ $\mathrm{cm})$ in length, are made. One incision is near the umbilicus, or navel, and one is between the umbilicus and the pubis, other incision is smaller on the right side of the lower abdomen. The surgeon then passes a camera and special instruments through these incisions. With the aid of this equipment, the surgeon visually examines the abdominal organs and identifies the appendix. The appendix is then freed from all of its attachments and removed. The place where the appendix was formerly attached, the cecum, is stitched. The appendix is removed through one of the incisions. The instruments are removed and then all of the incisions are closed [26]

The current study showed that there were no significant differences between both groups regarding operative time $(\mathrm{P}$-value $=0.179)$ and drain inserted $(\mathrm{P}$ value $=1.0$ )

Our results were supported by study of Yagmurlu et al., 2006. carried a comparative study between LA and OA for perforated appendix, no statistical significance was proved concerning the operative time. The mean time for LA was $61 \mathrm{~min}$ and OA was $57 \mathrm{~min}$ [26]

Furthermore, Lim et al., 2011. revealed that the operative time were $74.9 \pm 17.1$ minutes in the LA group and $86.3 \pm 30.7$ minutes in the OA group, but the difference was not statistically significant $(\mathrm{P}=0.309)$. [27]

Also, Shimoda et al., 2018. demonstrated that operating time did not differ between both groups [28]

In contrary with our results, Seqsaqa et al., 2020 reported that the operative time was significantly longer with LA than OA by 23.48 min that was nearly similar to many published literature [29]

These results could be explained as laparoscopic approach needs more experience, skills, and training. Dealing with complicated appendicitis needs meticulous dissection which needs furthermore skills and training. Also. Seqsaqa et al., 2020. reported that the need for intraperitoneal drain insertion was significantly lower with LA than OA $(p=0.001)$. This significance was also reported by Horvath et al. 2017; they explained that the laparoscopic technique offers a good vision to the entire abdomen and that enables the surgeon to achieve a careful suction from every quadrant having collections [30]

Also, Nazir et al., 2019 [31] revealed that the significantly shorter mean operating time for laparoscopic as compared to open appendectomy noted in our study differs from Muhammad et al.2013's [32]. findings, who reported the mean operating time as $75 \pm 23$ minutes for a laparoscopic appendectomy and $64 \pm 15$ minutes for an open appendectomy. Another study conducted by $\mathbf{L i n}$ et al., 2006. showed that 
laparoscopic appendectomy took a longer time to complete (96.1 \pm 43.1 minutes) than open appendectomy (67.8 \pm 32.2 minutes). Additional studies suggest the laparoscopic approach is associated with longer operating times than an open appendectomy. These results were in contradiction to ours. The variation reported in the literature in mean operating times may be due to variations in skill levels and experience with laparoscopic techniques in different centers [33]

Pradhan et al., 2015. demonstrated that the operative time in OA group was 37.99 minutes ( $S D=9.8)$ while that in LA group was 42.82 minutes $(\mathrm{SD}=10.8)$. The operative time decreased with the increasing experience. [34]

Furthermore, Manto glu et al., 2015. reported decreased operative time of LA (mean $41.42 \pm 10.32$ minutes) compared to OA (mean $46.25 \pm 18.84$ minutes) and explained that may be attributed to the fact that their team has enough experience with LA [35]

Open appendectomy has been the gold standard for treating patients with acute appendicitis for more than a century, but the efficiency and superiority of laparoscopic approach compared to the open technique is the subject of much debate nowadays. There is evidence that minimal surgical trauma through laparoscopic approach resulted in significant shorter hospital stay, less postoperative pain, faster return to daily activities in several settings related with gastrointestinal surgery. However, several retrospective studies, several randomized trials and meta-analyses comparing laparoscopic with open appendectomy have provided conflicting results. Some of these studies have demonstrated better clinical outcomes with the laparoscopic approach, while other studies have shown marginal or no clinical benefits and higher surgical costs [35]

In the study in our hands, there were no significant differences between both groups regarding duration to regain of fluid intake $(\mathrm{P}$-value $=0.251)$ and hospital stay $(\mathrm{P}$-value $=0.251[35]$.

However, in the study of Lim et al., 2011., the LA group took $2.1 \pm 1.2$ days to start soft diet whereas the OA group took $3.5 \pm 1.5$ days, showing the LA group took less time $(\mathrm{P}=0.001)$. The length of hospital stay was also significantly shorter $(\mathrm{P}=0.045)$ in the LA group $(4.4 \pm 2.3$ days $)$ than in the OA group $(5.8 \pm 2.9$ days) [36].

In the study of, IBRAHEEM et al., 2021 there was highly statistically significant decrease mean of laparoscopy group compared to open group according to post-operative recovery regarding time taken for return to normal work [37].

Also, Ali et al., 2018 [38] study showed that the mean length of hospital stay was shorter in the LA group $(34 \pm 13 \mathrm{~h}$. in LA vs. $40 \pm 1$ h in OA; $\mathrm{p}=0.01$ ).Svensson et al., 2016 [39] showed that laparoscopic appendectomy had a shorter median postoperative length of stay, 43 vs. 57 hours $(\mathrm{p}<0.05)$. In study by Karakus, et al., 2016 [40]. the hospital stays of LA group (2.15 \pm 0.7 days) is less than OA groups $(2.25 \pm 0.7$ days $)(\mathrm{p}<0.001)$
Furthermore, Pradhan et al., 2015 revealed that length of stay and time to return back to work were all lesser among patients who underwent laparoscopic appendectomy. Laparoscopic appendectomy took average $71.36 \mathrm{mts}$ and it is $9.05 \mathrm{mts}$ more than open appendectomy [41].

Laparoscopic appendectomy has gained much popularity among surgeons because of the use of minimally invasive techniques, but some remain skeptical about its use instead of open appendectomy. Those who criticize laparoscopic appendectomy cite the increased operative costs of using disposable instruments. Other criticisms of laparoscopic appendectomy target the increased operating time and increased incidence of intra-abdominal abscesses, particularly in cases of a perforated appendix. Proponents of laparoscopic appendectomy claim the procedure yields improved wound healing, reduced postoperative pain, and earlier discharge from the hospital, with an earlier return to normal activities [42].

Furthermore, laparoscopy has the advantages of minimal incision, a better view of the peritoneal cavity, and safe exploration. The feasibility and validity of the laparoscopic approach in complicated (i.e., perforated) appendix cases remain controversial, as it is associated with an increased incidence of intra-abdominal collection, but several other trials have statistically found that the laparoscopic approach is associated with fewer postoperative complications [43].

The present study showed that wound infection was significantly higher in group A (18\%) compared to group B (2\%); P-value was 0.008. No significant differences were reported between both groups regarding intra peritoneal collection $(\mathrm{P}$-value $=0.678)$, ileus $(\mathrm{P}$-value $=0.436)$, and readmission $(\mathrm{P}$-value $=$ 0.436). [43]

Our results were supported by study of Pradhan et al., 2015 as they reported that nine patients $(8.5 \%)$ in Group OA while, $3(2.5 \%)$ patients in Group LA developed postoperative wound infection at 1 week follow up [44].

Also, Seqsaqa et al., 2020 revealed that the rate of wound infection was lower in LA group than OA group, but the difference was not significant (20\% vs. $26.7 \%$ respectively, $\mathrm{p}=0.542$ ). There was no significant difference between the LA and OA groups regarding occurrence of postoperative intraperitoneal collection $(6.3 \%$ vs. $10 \%$ respectively) or ileus $(3.3 \%$ vs. $6.3 \%$ respectively). There was also non-significant difference between the two groups regarding readmission (3.3\% in LA group vs. $6.3 \%$ in OA group) [45].

Tuggle et al., 2010 demonstrated that superficial surgical site infection was $70 \%$ less likely to occur in LA (OR 0.304 P = 0.000), organ space infection was 2fold more likely to occur in LA (OR 2.19 P = 0.003), and dehiscence was $78 \%$ less likely to occur in LA (OR $0.22 \mathrm{P}=0.015$ ) [46].

In the study of Soltan et al., 2019, the laparoscopic technique was better in operative time ( $\mathrm{P}$ $=0.014)$, less intraoperative complication, less postoperative complications $(7.5 \%$ of all patients had 
complications postoperatively all in open group), less length of hospital stay $(\mathrm{P}=0.025)$, and less oral intake time $(\mathrm{P}=0.365)$ [47].

Marzouk et al. 2003 showed laparoscopic appendicectomy significantly improved the postoperative wound infection rate. There was no wound infection in the laparoscopic group, whereas in open group the infection rate was 7.6 [48].

According to Muhammad et al., 2013 [49] who reported that the rate of infections in the laparoscopic appendectomy group was $8.3 \%$ while that in the open appendectomy group was $24.4 \%$. Lin et al., 2006 [50] also showed that the rate of infections was significantly lower in laparoscopic appendectomy $(15.2 \%)$ than in open appendectomy $(30.7 \%)$. This may be attributed to the fact that laparoscopic appendectomy requires less manipulation of the gut by the surgeon's hands and instruments as compared to open appendectomy. Furthermore, the gut does not come into contact with the incision in the layers of the anterior abdominal wall during laparoscopic appendectomy as the appendix is explored in situ [50]

Kumar \& Rao, 2018 stated that post-operative complications like vomiting and ileus were lower in laparoscopic group. There is significant reduction in incidence of post-operative wound infection in laparoscopic group [51].

Furthermore, Biondi et al., 2016 observed a greater overall incidence of complications in open surgery than in laparoscopic surgery. A total of 29 complications occurred in the laparoscopic group, while 55 complications occurred in the open appendectomy group. They did not observe a significant difference between groups in vomiting, paralytic ileus, intrabdominal abscesses and hemoperitoneum. Differences in wound infection and wound dehiscence were significant $(\mathrm{P}<0.001)$ [51]

\section{Conclusion}

Laparoscopic appendectomy is superior to open appendectomy in complicated cases in terms of wound site infections. The operating time depends on the surgical skills of the operating surgeon and the magnitude of the condition. With regards to the length of hospital stay, there is no difference between the two techniques. Thus, the laparoscopic appendectomy can be safely adopted for the removal of the perforated appendix.

\section{References}

[1] YangJ $^{1}$, Yu K, Li W, Si X, Zhang J, Wu W, \& Cao.Y, Laparoscopic Appendectomy for Complicated-Acute Appendicitis.

SurgLaparoscopic Endosc-Percutan-Tech. 2017 Oct;27(5):366-368

[2] Tannoury \& Abboud B. Treatment options of inflammatory appendiceal masses in adults. World J Gastroenterol. 2013, 19(25):3942-3950

[3] YehB.Evidence-based-emergency medicine/rational clinical examination abstract. Does this adult patient have appendicitis? Ann Emerg Med. 2008 Sep. 52(3):301-3
[4] Kim JK, Ryoo S, Oh HK, Kim JS, Shin R \& ChoeEK. Management of appendicitis presenting with abscess\&mass. J-KoreanSocColoproctol. 2010;26(6):413-419

[5] Bachar I, Perry ZH, Dukhno L, Mizrahi S\&Kirshtein B. Diagnostic value of laparoscopy, abdominal computed tomography, and ultrasonography in acute appendicitis. $\mathbf{J}$ LaparoendoscAdvSurg Tech A. 2013 Dec. 23 (12):982-9

[6] Karamanakos SN, Sdralis E, Panagiotopoulos S\&Kehagias I. Laparoscopy in the emergency setting: a retrospective review of 540 patients with acute abdominal pain. SurgLaparoscEndoscPercutan Tech. 2010 Apr. 20 (2):119-24

[7] Kim SH, Park SJ, Park YY\& Choi SI. Delayed Appendectomy Is Safe in Patients with Acute Nonperforated Appendicitis. Int Surg. 2015 Jun. 100 (6):1004-10

[8] Ruffolo C, Fiorot A, Pagura G, Antoniutti M, Massani M, Caratozzolo E, Bonariol L, Calia di Pinto F\& Bassi N. Acute appendicitis: what is the gold standard of treatment.World J Gastroenterol. 2013 Dec 21;19(47):8799-807

[9] BallCG, KortbeekJB , KirkpatrickAW \& Mitchell.P. Laparoscopic appendectomy for complicated appendicitis: an evaluation of postoperative factors .SurgEndosc. 2004 Jun;18(6):969-73

[10] Amyand, Claudius (1735). "of an inguinal rupture with a pin in the appendix caeci, incrusted with stone; and some observation de on wounds in the guts". Philosophical Transactions of the Royal Society of London.39(443): 329-336

[11] McBurney C IV. The Incision made in the abdominal wall in cases of Appendcitis with Description of a New mrthod of operating.ANN SURG 1894; 20 38-43

[12] Semm K Endoscopic Appendectomy. Endoscopy 1983; 15 59-64

[13] Tuggle, K. R. M., Ortega, G., Bolorunduro, O. B., Oyetunji, T. A., Alexander, R., Turner, P. L., ... \& Fullum, T. M. (2010). Laparoscopic versus open appendectomy in complicated appendicitis: a review of the NSQIP database. Journal of Surgical Research, 163(2), 225-228.

[14] Athanasiou, C., Lockwood, S., \& Markides, G. A. (2017). Systematic review and metaanalysis of laparoscopic versus open appendicectomy in adults with complicated appendicitis: an update of the literature. World journal of surgery, 41(12), 3083-3099.

[15] Quah, G. S., Eslick, G. D., \& Cox, M. R. (2019). Laparoscopic appendicectomy is superior to open surgery for complicated appendicitis. Surgical endoscopy, 33(7), 20722082.

[16] Alsoueni, H., Mohammed, M., \& Nawar, A. (2020). Laparoscopic Appendectomy Versus Open Appendectomy in Young Female 
Patients. Benha medical journal, 37(1), 271284.

[17] Alnjadat I, Abdallah B. (2013). Alvarado versus RIPASA score in diagnosing acute appendicitis. Rawal Med J. 38:147-51.

[18] IBRAHEEM, M., SAYED, A. A. A., \& RAAFAT, I. (2021). A Comparative Study of Laparoscopic and Open Appendectomy. The Medical Journal of Cairo University, 89(March), 155-161.

[19] Pradhan, S., Shakya, Y. R., Batajoo, H., Malla, B., Joshi, H. N., Thapa, L. B., \& Makaju, R. K. (2015). Laparoscopic versus open appendectomy: a prospective comparative study. Journal of Society of Surgeons of Nepal, 18(2), 29-32.

[20] Mohamed AA, Mahran KM. (2013). Laparoscopic appendectomy in complicated appendicitis: Is it safe? J Minim Access Surg. Apr; 9(2):55-8.

[21] Hui TT, Major KM, Avital I, Hiatt JR, Margulies DR. (2002). Outcome of elderly patients with appendicitis: effect of computed tomography and laparoscopy. Arch Surg. Sep; 137(9):995-8; discussion 999-1000.

[22] Lunca S, Bouras G, Romedea NS. (2004). Acute appendicitis in the elderly patient: diagnostic problems, prognostic factors and outcomes. Rom J Gastroenterol. 2004 Dec; 13(4):299-303.

[23] Biondi A, Grosso G, Mistretta A, Marventano S, Toscano C, Drago F et al. (2013). Laparoscopic vs. open approach for colorectal cancer: evolution over time of minimal invasive surgery. BMC Surg.; 13(2): S12.

[24] Bhosle, R. V., \& Degloorker, G. G. (2018). A retrospective comparative study of laparoscopic appendectomy and open appendectomy. International Surgery Journal, 5(7), 2612-2615.

[25] Biondi, A., Di Stefano, C., Ferrara, F., Bellia, A., Vacante, M., \& Piazza, L. (2016). Laparoscopic versus open appendectomy: a retrospective cohort study assessing outcomes and cost-effectiveness. World Journal of Emergency Surgery, 11(1), 1-6.

[26] Yagmurlu A, Vernon A, Barnhart DC, Georgeson KE, Harmon CM. (2006). Laparoscopic appendectomy for perforated appendicitis: a comparison with open appendectomy. Surg Endosc; 20:1051-1054.

[27] Lin HF, Wu JM, Tseng LM, Chen KH, Huang SH, Lai IR. (2006). Laparoscopic versus open appendectomy for perforated appendicitis. J Gastrointest Surg .10:906-910.

[28] Shimoda, M., Maruyama, T., Nishida, K., Suzuki, K., Tago, T., Shimazaki, J., \& Suzuki, S. (2018). Comparison of clinical outcome of laparoscopic versus open appendectomy, single center experience. Heliyon, 4(5), e00635.
[29] Seqsaqa, M., Rozeik, A. E., Khalifa, M., \& Ashri, H. N. A. (2020). Laparoscopic versus open appendectomy in complicated appendicitis in children: a single center study. Egyptian Pediatric Association Gazette, 68(1), 1-5.

[30] Horvath P, Lange J, Bachmann R, Struller F, Königsrainer A, Zdichavsky M (2017) Comparison of clinical outcome of laparoscopic versus open appendectomy for complicated appendicitis. Surg Endosc 31(1):199-205.

[31] Nazir, A., Farooqi, S. A., Chaudhary, N. A., Bhatti, H. W., Waqar, M., \& Sadiq, A. (2019). Comparison of open appendectomy and laparoscopic appendectomy in perforated appendicitis. Cureus, 11(7).

[32] Mohamed AA, Mahran KM. (2013). Laparoscopic appendectomy in complicated appendicitis: Is it safe? J Minim Access Surg. Apr; 9(2):55-8.

[33] Lin HF, Wu JM, Tseng LM, Chen KH, Huang SH, Lai IR. (2006). Laparoscopic versus open appendectomy for perforated appendicitis. J Gastrointest Surg ;10:906-910.

[34] Pradhan, S., Shakya, Y. R., Batajoo, H., Malla, B., Joshi, H. N., Thapa, L. B., \& Makaju, R. K. (2015). Laparoscopic versus open appendectomy: a prospective comparative study. Journal of Society of Surgeons of Nepal, 18(2), 29-32.

[35] MANTO־GLU B., KARIP B., MESTAN M., I. ,SCAN Y., A ${ }^{\smile}$ GCA B., ALTUN H. and MEMI SO־GLU K. (2015): Should appendectomy be performed laparoscopically? Clinical prospective randomized trial. Turkish Journal of Surgery/ Ulusal cerrahi dergisi, 31 (4): 224.

[36] Lim, S. G., Ahn, E. J., Kim, S. Y., Chung, I. Y., Park, J. M., Park, S. H., \& Choi, K. W. (2011). A clinical comparison of laparoscopic versus open appendectomy for complicated appendicitis. Journal of the Korean Society of Coloproctology, 27(6), 293.

[37] IBRAHEEM, M., SAYED, A. A. A., \& RAAFAT, I. (2021). A Comparative Study of Laparoscopic and Open Appendectomy. The Medical Journal of Cairo University, 89(March), 155-161.

[38] ALI R., ANWAR M. and AKHTAR J. (2018): Laparoscopic versus open appendectomy in children: A randomized controlled trial from a developing country. Journal of Pediatric Surgery, 53 (2): 247-9.

[39] Svensson JF, Patkova B, Almström M, Eaton S, Wester T (2016) Outcome after introduction of laparoscopic appendectomy in children: a cohort study. J Pediatr Surg 51(3):449-453.

[40] KARAKUS, O.Z., ULUSOY O., ATES , O., HAKGÜDER G., OLGUNER M. and AKGÜR F.M. (, 2016): Conventional singleport laparoscopic appendectomy for complicated appendicitis in children: Efficient 
and cost-effective. Journal of Minimal Access Surgery, 12 (1): 16.

[41] Pradhan, S., Shakya, Y. R., Batajoo, H., Malla, B., Joshi, H. N., Thapa, L. B., \& Makaju, R. K. (2015). Laparoscopic versus open appendectomy: a prospective comparative study. Journal of Society of Surgeons of Nepal, 18(2), 29-32.

[42] Semm K Endoscopic Appendectomy. Endoscopy 1983; 15 59-64

[43] Tuggle, K. R. M., Ortega, G., Bolorunduro, O. B., Oyetunji, T. A., Alexander, R., Turner, P. L., ... \& Fullum, T. M. (2010). Laparoscopic versus open appendectomy in complicated appendicitis: a review of the NSQIP database. Journal of Surgical Research, 163(2), 225-228.

[44] Pradhan, S., Shakya, Y. R., Batajoo, H., Malla, B., Joshi, H. N., Thapa, L. B., \& Makaju, R. K. (2015). Laparoscopic versus open appendectomy: a prospective comparative study. Journal of Society of Surgeons of Nepal, 18(2), 29-32.

[45] Seqsaqa, M., Rozeik, A. E., Khalifa, M., \& Ashri, H. N. A. (2020). Laparoscopic versus open appendectomy in complicated appendicitis in children: a single center study. Egyptian Pediatric Association Gazette, 68(1), 1-5

[46] Tuggle, K. R. M., Ortega, G., Bolorunduro, O. B., Oyetunji, T. A., Alexander, R., Turner, P. L., ... \& Fullum, T. M. (2010). Laparoscopic versus open appendectomy in complicated appendicitis: a review of the NSQIP database. Journal of Surgical Research, 163(2), 225-228.

[47] Soltan, H. M., El-Tatawy, A. G., \& Alsegaey, A. H. (2019). Laparoscopic versus open appendectomy in complicated acute appendicitis. Menoufia Medical Journal, 32(2), 554.

[48] Marzouk M, Khater M, Elsadek A. Abdelmoghny. (2003). Laparoscopic vs open appendicectomy: a prospective comparative study of 227 patients. Surg Endosc.; 17:721-4.

[49] Mohamed AA, Mahran KM. (2013). Laparoscopic appendectomy in complicated appendicitis: Is it safe? J Minim Access Surg. Apr; 9(2):55-8.

[50] Lin HF, Wu JM, Tseng LM, Chen KH, Huang SH, Lai IR. (2006). Laparoscopic versus open appendectomy for perforated appendicitis. J Gastrointest Surg ; 10:906-910.

[51] Kumar, S. G., \& Rao, D. N. (2018). Open VS laparoscopic appendicectomy: A comparative Study. International J Surg Sci, 2(2), 19-22. 